\section{Para além dos rankings globais: construindo uma New Flagship University}

\section{Beyond the global rankings: building a New Flagship University}

DOUGLASS, John Aubrey (ed.). The New Flagship University: changing the paradigm from global ranking to national relevancy. Nova York, Palgrave Macmillan, 2016. 217 páginas.

Ana Maria Nunes Gimenez $(1)$

http://orcid.org/0000-0002-6187-0718

Maria Beatriz Machado Bonacelli (2)

(iD) http://orcid.org/0000-0003-0795-7684

DOI: $10.1590 / 3410103 / 2019$

(1) Universidade Estadual de Campinas (Unicamp) e Instituto Nacional de Ciência e Tecnologia em Políticas

Públicas, Estratégias e Desenvolvimento (INCT/

PPED), Campinas - SP, Brasil.

E-mail: anamarianunesgimenez@gmail.com.

(2) Universidade Estadual de Campinas (Unicamp) e Instituto Nacional de Ciência e Tecnologia em Políticas

Públicas, Estratégias e Desenvolvimento (INCT/ PPED), Campinas - SP, Brasil.

E-mail: bia@ige.unicamp.br.

Este livro, editado por John Aubrey Douglass, pesquisador sênior em políticas públicas e educação superior no Center for Studies in Higher Education (CSHE), da Universidade da Califórnia (Berkeley), fornece uma visão abrangente do perfil e papel das principais universidades nacionais, ou seja, universidades públicas que assumiram papel de liderança em seus respectivos países. A abordagem de Douglass se coloca como uma narrativa alternativa para os rankings globais e para a busca pelo status de WCU (World Class University/Universidade de Classe Mundial), temas que têm chamado a atenção e dominado as pautas de discussão de universidades e de governos ao redor do mundo.

Muitas das discussóes realizadas na obra, especialmente nos quatro primeiros capítulos, já haviam sido direta ou indiretamente levantadas por Clark Kerr, em The uses of universities (lançada em 1963), ${ }^{1}$ na qual descreveu uma universidade de pesquisa e ensino animada pela descoberta contínua, pela mudança, crescimento e desenvolvimento nacional. Kerr foi reitor em Berkeley, entre 1952 e 1957, presidente do Sistema da Universidade da Califórnia, de 1958 a 1967, e figura central na elaboração do Plano Diretor de 1960, que ajudou a moldar o ensino superior em todo o país, servindo, inclusive, de inspiração para outros países (Marginson, 2016). Segundo Kerr (2005, pp. 27-28), a multiversidade

[...] é uma instituição multifuncional. Ela não é uma única comunidade, mas várias - a comunidade dos alunos da graduação, dos pós-graduandos; a comunidade dos humanistas, a comunidade dos cientistas sociais e a comunidade dos cientistas das exatas; as comunidades das escolas profissionais; a comunidade de todos os funcionários não acadêmicos, a comunidade dos administradores. Seus limites são imprecisos - ela alcança até os ex-alunos, legisladores, agricultores, empresários, os quais se relacionam com uma ou mais dessas comunidades internas.

É justamente com fundamento nessa ideia de "multiversidade", ou seja, que a universidade é uma organização complexa, multifacetada e que não pode ficar apartada do resto da sociedade, pois engloba muitos públicos e muitas missóes, devendo atuar em benefício das sociedades que são a sua razão de existir, é que Douglass apela, especialmente, aos ministérios, mas também aos dirigentes universitários, para que considerem o modelo da New Flagship University (NFU) como um caminho viável na busca pela excelência acadêmica, pois o autor entende que "os esforços onipresentes dos ministérios e de muitas universidades na busca por classificações mais elevadas têm consequências prejudiciais" (p. 4). A ênfase na adoção do paradigma atual da WCU, que tem focalizado os incentivos na produtividade da pesquisa, comumente ocorre em detrimento dos outros papéis vitais que também cabem às principais universidades públicas de cada país, em termos de serviço público e de mobilidade socioeconômica, por exemplo. 
A obra está dividida em duas partes e nove capítulos, sendo a primeira, sob responsabilidade do editor (John A. Douglass), formada por quatro capítulos que introduzem a temática geral, preparando caminho para as discussóes dos capítulos subsequentes. Nessa primeira parte, o autor discorre sobre a origem das flagships universities, suas principais características, bem como apresenta os elementos ou características que representam o ideal da NFU. Segundo o autor, o termo flagship university surgiu nos Estados Unidos e tem inspiração náutica, ou seja, flagship é o principal navio de uma Marinha e o responsável por conduzir e coordenar as manobras navais.

A origem da flagship ideia remonta ao século XIX, quando surge o modelo híbrido de universidade pública dos Estados Unidos, da união da tradição inglesa (residential college) ao modelo emergente de universidade humboldtiana (fundada na pesquisa e na pós-graduação), mas também incorporando uma relevância utilitarista, que deu o tom para o ensino e a pesquisa, notadamente a fim de alavancar a mobilidade socioeconômica e o desenvolvimento da nação (com impulso dos Land Grant Acts). ${ }^{2}$ Sendo assim, as flagship universities normalmente são universidades públicas que alcançaram uma posição de destaque e liderança nos seus respectivos países, são abrangentes e intensivas em pesquisa, altamente seletivas, detêm os melhores alunos e docentes, e, além disso, se beneficiaram historicamente de financiamentos mais robustos para dar sustentação às suas missões, a saber, ensino, pesquisa e serviço público. Douglass conclui que os dados das pesquisas apresentadas nos demais capítulos indicam que praticamente todos os países do mundo dispóem de Flagships universities, que ele chama de Traditional Flagship University, para diferenciar do novo modelo proposto, que o autor descreve analiticamente. Essas universidades tradicionais são o reflexo das diferenças contextuais que envolvem aspectos culturais, políticos, bem como as expectativas e as realidades de seus ambientes socioeconômico, mas que seria importante que governos e líderes universitários atuassem no sentido de favorecer e viabilizar a incorporação dos ideais do modelo da NFU para uma contribuição mais abrangente aos seus países.
Douglass também problematiza o crescimento da importância dos rankings globais e a relevância (exacerbada) pela conquista da condição de WCU, Universidade de Classe Mundial, defendendo a ideia de que o modelo da NFU pode ser um caminho viável para a conquista do status de classe mundial, mas que o contrário não é verdadeiro, ou seja, o atual modelo de WCU, baseado em métricas e indicadores limitados, não possibilita que uma universidade se transforme em uma NFU. No entanto, o autor não refuta de todo os rankings, muito menos o engajamento internacional, até porque entende que a relevância nacional e regional e o engajamento internacional não são objetivos mutuamente incompatíveis, pelo contrário, a presença equilibrada desses elementos é que caracteriza "as melhores universidades" (p. 40). Apenas entende que os rankings globais deveriam representar uma preocupação secundária e não um fim em si mesmo. "A rota sequencial lógica é do envolvimento regional/nacional e depois a influência global” (p. 7). Este pensamento é bastante convergente com a ideia da universidade "glocal", que tem sido discutida por alguns estudiosos, especialmente no âmbito da Global University Network for Innovation (GUNi). ${ }^{3}$ Entende-se que uma universidade "glocal" é a que promove "a interação entre a visão global e os impactos locais das suas atividades" (Grau, 2014, p. 2). Para que o fenômeno da "glocalização" torne-se uma realidade, necessariamente, estes três elementos precisam caminhar juntos: "a globalização, a localização e as universidades" (Grau et al., 2017, p. 497).

A partir do quinto capítulo são apresentadas as contribuiçóes de autores que discutem o papel das principais universidades asiáticas, russas, escandinavas e latino-americanas, com o objetivo de identificar quanto o modelo NFU pode ser relevante para os países e universidades e até que ponto os rankings globais e a ideia de WCU têm influenciado a formulação de políticas nacionais e os comportamentos institucionais.

O capítulo 5, sob a chancela de John N. Hawkins (Universidade da Califórnia, Los Angeles), aborda o ensino superior na Ásia. Na China, por exemplo, somente um reduzido grupo de universidades de elite recebeu grandes investimentos do governo para a realizaçáo de pesquisas de alto 
nível. ${ }^{4}$ Além disso, houve expressivo aumento do número de universidades, o que tem gerado grandes disparidades entre os níveis de qualidade dessas instituiçôes, refletido no aumento substancial do número de graduados desempregados ou subempregados. Em termos gerais, as universidades asiáticas ainda estâo fortemente vinculadas à "estratégia de imitaçáo (em grande parte do ensino superior dos Estados Unidos e da Europa Ocidental, focada principalmente na produtividade da pesquisa)" ( $\mathrm{p}$. 130), o que tem limitado as possibilidades de criarem abordagens inovadoras para seus sistemas de educação superior, além de isso ser altamente dispendioso. No entanto, o autor salienta que os formuladores de política já têm demonstrado interesse em buscar alternativas ao modelo das WCUs, em prol de interaçáo mais harmônica entre o ensino, a pesquisa e o serviço público.

Andrés Bernasconi e Daniela V. Calderón (Pontifícia Universidade Católica do Chile) são os autores do capítulo 6, no qual discutem a origem das universidades latino-americanas e a contribuição destas à construção de identidades nacionais e coesão social na regiâo, até o estágio atual, apontando os principais obstáculos à instauração de uma NFU. Para os autores, universidades de pesquisas abrangentes são difíceis de serem encontradas em países em desenvolvimento, particularmente na América Latina, considerando que "talvez duas ou três universidades" brasileiras possam ser enquadradas nessa categoria (p. 144). Os autores concluem que o enquadramento das principais universidades latino-americanas no modelo NFU depende, entre outros, dos seguintes fatores: financiamento adequado, fortalecimento da liderança e melhoria dos processos de governança, contratação de docentes com doutorado, estímulo à pós-graduação e à pesquisa avançada, engajamento mais amplo com a sociedade (desenvolvimento e amadurecimento da terceira missão), especialmente em nível regional. Enquanto essas mudanças não ocorrerem, o "modelo New Flagship [...] permanecerá mais como uma referência para a maioria das principais universidades latino-americanas do que um ideal realizado" (p. 150).

No capítulo 7, Bjørn Stensaker e Tatiana Fumasoli (Universidade de Oslo) tratam do ensino superior na Escandinávia, com foco nas universidades de Copenhague, de Oslo e de Estocolmo, pontuando como essas instituiçóes têm se movido, satisfatoriamente, na direção do modelo NFU ao longo do tempo. Segundo os autores, as principais universidades escandinavas são "públicas, relativamente antigas, abrangentes e intensivas em pesquisa, financiadas em grande parte por governos nacionais, localizadas em áreas urbanas e geralmente reconhecidas como instituiçóes centrais da sociedade" (p. 154). A existência de uma cultura sedimentada na cooperação é um dos grandes diferenciais das universidades escandinavas, o que proporciona elas se moverem constantemente em busca de colaboraçóes para além de seus muros, dialogando e criando pontes com outros atores estratégicos, estimulando e fortalecendo a produtividade acadêmica, inserindo-se no contexto global e, especialmente, apoiando as comunidades regionais. A presença de todos esses elementos permite o enquadramento dessas universidades no modelo NFU.

Isak Froumin e Oleg Leshukov (Universidade Nacional de Pesquisa, Moscou), autores do capítulo 8 , traçam um histórico do desenvolvimento das universidades russas desde a época da União Soviética até os dias atuais. Segundo eles, todas as universidades eram meras "engrenagens da máquina do governo central" (p. 173). ${ }^{5}$ Sob a égide do modelo soviético, a maioria das universidades tradicionais (as flagships) não tinham autoridade para conduzir pesquisa básica em campos científicos e tecnológicos, que era da competência da Academia Russa de Ciências. Após a Guerra Fria, entretanto, foram incorporadas novas visōes acerca do papel das universidades. Com a relativa flexibilizaçáo do controle estatal, elas passaram, progressivamente, a conquistar mais autonomia para ampliarem o seu escopo de atuação e a definirem seus próprios critérios de seleção de estudantes. Além disso, o governo começou a valorizar as comparaçôes internacionais, a produtividade e a ambicionar que suas principais universidades conquistassem o status de classe mundial (WCU). Isso provocou uma situação caótica e de insegurança, em que algumas universidades não conseguiram se ajustar à nova realidade, o que resultou em processos sucessivos de fusóes, originando novas instituiçóes. Os autores concluem que, atualmente, as principais universidades nacionais 
da Rússia precisam adotar uma visão mais abrangente de sua missão e papel na sociedade, melhorar os seus programas de pós-graduação, especialmente o doutorado, valorizar mais a internacionalização, não apenas por meio da interação com atores globais, mas, especialmente, a partir do recrutamento de docentes, reconhecendo que todas essas questóes dependem de financiamento adequado.

O epílogo da obra (capítulo 9), de autoria de Manja Klemenčič (Universidade Harvard), realiza um apanhado geral das discussóes, enfatizando que as principais universidades nacionais e todas as que buscam alcançar esse status necessitam desenvolver uma visão mais abrangente e aprofundada do seu papel nas sociedades que as financiam, para que possam se transformar efetivamente em new flagship universities. Segundo a autora, os rankings universitários globais estão ordenando o sistema global de ensino superior e isso tem gerado insatisfações, pois a competição por posições de destaque nesses rankings vem deslocando a atenção das universidades e fazendo que percam a noção do que a excelência abrange e o que é relevante para cada país. Portanto, é necessário que busquem o seu autoaperfeiçoamento e se engajem mais significativamente com as sociedades "que lhes deram vida e propósito" (p. 191).

Trata-se, portanto, de uma obra indispensável a todos os envolvidos com a temática da educação superior, sejam eles pesquisadores, dirigentes universitários, autoridades governamentais e formuladores de políticas, e também para aqueles que procuram compreender um pouco mais acerca dos desafios e das perspectivas atuais que se colocam para as instituições de educação superior, em tempos de crescente importância dos rankings globais, que pode levar a um obscurecimento dos reais propósitos e papéis que as universidades públicas (especialmente, mas não exclusivamente) devem desempenhar em seus países.

Do primeiro ao último capítulo, o embasamento conceitual da obra está respaldado em trabalhos de autores de renome internacional, que têm desenvolvido estudos no campo da educação superior sob os mais diferentes aspectos e nuances: internacionalização, governança, massificação, acesso e equidade, empreendedorismo acadêmico (hélice tríplice), entre outros, o que demonstra a riqueza e a diversidade de temas e enfoques presentes em cada capítulo.

\section{Notas}

1 Em 1963, Clark Kerr ministrou uma série de palestras na Universidade de Harvard, para discutir as transformaçóes que o ensino superior dos Estados Unidos vinha enfrentando. Essas palestras deram origem aos três primeiros capítulos da obra. A partir dos anos 1970, o autor foi incorporando novos capítulos, até chegar ao nono e último capítulo, em 2001.

2 Duas leis federais, os Morrill Acts (1862 e 1890), que permitiram a doação de terras federais aos estados, com a finalidade de financiar universidades/faculdades que pudessem contribuir especialmente para o desenvolvimento agrícola e industrial, dando origem aos land grant colleges dos Estados Unidos.

3 A GUNi é uma rede criada em 1999 e apoiada pela Unesco, a Universidade das Naçóes Unidas e a Associação Catalã de Universidades Públicas, com a missão de estimular a cooperaçáo internacional entre universidades. Atualmente, a rede conta com mais de 210 membros, de 78 países. Disponível em: <http:// www.guninetwork.org>.

4 Zong e Zhang (2017) entendem que os investimentos seletivos com vistas à melhoria da qualidade do ensino e da pesquisa e à conquista de melhores posiçóes nos rankings globais escondem disparidades significativas, mesmo entre o reduzido grupo de universidades selecionadas para compor o primeiro escaláo das universidades chinesas (cerca de 40 universidades). Os autores observaram que, na primeira fase do projeto, o governo chinês destinou em torno de $50 \%$ de todo o orçamento a apenas nove universidades, integrantes da China's Ivy League - C9.

5 Drèze e Debelle (1983) explicam que esse modelo de universidade nasceu da adaptação do modelo napoleônico aos imperativos do regime soviético, qual seja: "a edificação da sociedade comunista" (p. 102). Nesse contexto, a universidade foi vista como um fator de produção que deveria fornecer formação profissional e política, assim como garantir a estabilidade do Estado. 


\section{BIBLIOGRAFIA}

DRÈZE, J. H. \& DEBELLE, J. (1983), Concepçóes da universidade. Trad. Francisco de Assis Garcia e Celina Fontenele Garcia. Fortaleza, EdUFCE.

GRAU, F. X. (2014), The "glocal" university. Disponível em: <http://www.guninetwork.org/files/ glocal-university_fx_grau_2014.pdf $>$. Acesso em: 9 nov. 2018.

GRAU, F. X. et al. (2017), "Recommendations for academia, academic leaders and higher education and research policymakers", in Grau et al. (eds.), Higher education in the world 6: towards a socially responsible university: balancing the global with the local, Girona, GUNi. Disponível em: <http://www.guninetwork.org/files/ download_full_report.pdf $>$. Acesso em: 9 nov. 2018.

KERR, C. (2005), Os usos da universidade. 15. ed. Brasília, Editora da UnB.

MARGINSON, S. (2016), The dream is over: the crisis of Clark Kerr's California idea of higher education. Oakland, University of California Press.

ZONG, X. \& ZHANG, W. (2017), “Establishing world-class universities in China: deploying a quasi-experimental design to evaluate the net effects of Project 985". Studies in Higher Education, 44 (1): 1-15. Disponível em: <https:// doi.org/10.1080/03075079.2017.1368475>. Acesso em: 11 mar. 2019. 